\title{
Studies on Nutrient Acquisition by Mycorrhizal Plants at Various Levels of Induced Sodicity
}

\author{
L. Srimathi Priya ${ }^{1 *}$, K. Indhumathi ${ }^{1}$, K. Kumutha ${ }^{2}$ and P. Pandiyarajan ${ }^{3}$ \\ ${ }^{1}$ Department of Fruit Science, Horticultural College \& Research Institute for Women, Tamil \\ Nadu Agricultural University, Navalur kuttapattu, Trichy -620027, India \\ ${ }^{2}$ Department of Agricultural Microbiology, Agricultural College \& Research Institute, Tamil \\ Nadu Agricultural University, Madurai, India \\ ${ }^{3}$ Department of Agricultural Microbiology, Anbil Dharmalingam Agricultural College, \\ Trichy-641 009, India \\ *Corresponding author
}

\section{A B S T R A C T}

\section{Keywords \\ Mycorrhiza, Glomus, Scutellospora, Onion, Rhizosphere}

Article Info

Accepted:

17 August 2020 Available Online: 10 September 2020
The role of AM (Arbuscular mycorrhizal) fungi in the rhizosphere of onion at induced salt stress was studied. A pot culture experiment was set up with three levels of salts and six treatments involving mycorrhizal inoculations with host crop as onion. The initial observations of the soil physico-chemical analysis on comparison with postharvest soil revealed that there was significant difference in nutrient availability as well as uptake by the plants. The percentage increase in nutrient contents over control was observed to be the highest in treatments with Glomus intraradices and Scutellospora calospora. Interestingly the native isolate from Trichy sodic soil was found to be on par with the standard isolates which made the study to render a valuable finding and the reasons are also discussed.

\section{Introduction}

The beginning of twenty first century is marked by environmental pollution and increased salinization of soil and water. Crops grown on saline soils suffer due to high osmotic stress, nutritional disorders and toxicities, poor soil physical conditions and reduced crop productivity. The direct effects of salt on plant growth may involve physiological drought, toxicity of excessive
$\mathrm{Na}^{+}$and $\mathrm{Cl}^{-}$ions and nutrient imbalance of soil solution as well as in the plant caused by nutrient uptake and/or transport to the shoot leading to ion deficiencies (Marschner, 1995).

Arbuscular mycorrhiza (AM fungi), a fungal biofertilizer improve, plant growth and nutrient uptake (viz., Phosphorus, Nitrogen, Zinc, and Copper) in plants and are beneficial in the biological control against biotic and abiotic stress. Arbuscular mycorrhizae 
development frequently leads to increased plant uptake of $\mathrm{P}$ and several micro nutrients through an increased exploitation of the soil volume. An increased exploitation is especially important for the uptake of less mobile nutrients like $\mathrm{P}, \mathrm{Zn}$ and $\mathrm{Cu}$. In mycorrhizal plants, the uptake rate of $\mathrm{P}$ per unit root length is two to three times higher than in non-mycorrhizal plants (McGonigle and Fitter, 1988). AM fungi, by their adequate supply of $\mathrm{P}$ enables the plants to thrive under stress conditions (Barea et al., 1992). Improved salt tolerance due to inoculation of Glomus mosseae (AM fungi) in tomato was proved by Al-karaki (2000) along with better mineral nutrition, particularly phosphorus at various levels of salt stress than the nonmycorrhizal tomatoes. Aliasgharzadeh et al., (2001) evaluated the distribution of arbuscular mycorrhizal fungi in the Tabriz plain, where soil salinity levels ranged from 7.3 - 9.2 dSm 1 and observed a close correlation lied between root colonization, and spore density with available $\mathrm{P}$ in soil. The concentration of nutrients $(\mathrm{P}, \mathrm{Zn}$, and $\mathrm{Cu})$ decreased with the increasing levels of salinity, but were higher than those of the non-mycorrhizal plants. Also, in mycorrhizal plants $\mathrm{Na}$ concentration were found to get lowered as salinity levels increased (Giri et al., 2007). Turkmen et al., (2008) studied the effect of two mycorrhizal genus $G$. intraradices and Gigaspora margarita on growth and nutrient contents of pepper seedlings grown under moderate salt stress $(7.5 \mathrm{ppm} \mathrm{NaCl})$ and observed that plant growth parameters and nutrient contents $(\mathrm{P}$, $\mathrm{K}, \mathrm{Ca}$ and $\mathrm{Na}$ ) had positive effects in tolerating salinity and on comparison, the performance of $G$. intraradices was found to be better than that of $G$. margarita. Mycorrhizal inoculations have shown to reduce the $\mathrm{Na}$ uptake and increased the $\mathrm{K}$ uptake in leaves of lettuce, increasing the salinity tolerance of the plants (Kohler et al., 2010).
Among various environmental stresses, soil salinity is one of the most devastating, which causes major reductions in cultivated land area, crop productivity and quality (Shahbaz and Ashraf, 2013). However, the need for enhancing the crop productivity is inevitable to feed the fast growing population.

This paper deals with the augmentation of nutrient uptake in plants under salt stress conditions by colonization of the AM fungi in the rhizosphere of onion. The use of biofertilizers can mitigate salinity effects on vegetables and reduce soil salinization by enhancing the nutrient status, growth and yield of the plants by either replacing soil nutrients, by making nutrients more available to plants, and/or by increasing plant access to nutrients. For e.g. the endomycorrhizal fungi Arbuscular mycorrhiza, improve plant growth and nutrient uptake (viz., Phosphorus, Nitrogen, Zinc, and Copper) in plants and are beneficial in the biological management of biotic and abiotic stress (Sanjoy kumar et al., 2011).

Also they aggregate soil particles (due to production of Glomalin protein through their hyphae) which is another lag in saline soil and thereby impart tolerance to salt stress. Biofertilizers can reduce soil salinization by reducing application of fertilizers, improving soil fertility by fixing atmospheric $\mathrm{N}$, both in association with plant roots and independent of roots, solubilizing insoluble soil phosphates and producing plant growth substances in the soil (Machado and Serralheiro, 2017). Here comes the need of the study, to understand better about the salinity tolerance of AM plants.

With this background, a study was taken up with the objective to evaluate the effect of AM fungal isolates at various levels of salinity in onion through a pot culture experiment. 


\section{Materials and Methods}

A pot culture study was taken up to analyze the influence of AM inoculation in salinity tolerance in Onion. Pots of $12 \mathrm{Kg}$ capacity were filled with sterilized pot mix soil followed by AM inoculation @ $50 \mathrm{~g}^{-1}$ pot. Screened isolates of AM (TRY 1, TRY 2, TRY 3 and TFS 1) along with two standard cultures ( $G$. intraradices and $S$. calospora) were used as inoculants while control was maintained without AM inoculation with salt treatment alone. Onion bulbs were planted (45 bulbs pot $^{-1}$ ) and then subjected to three levels of salinity $\left(1.5,3.0\right.$ and $\left.4.5 \mathrm{dSm}^{-1}\right)$ by addition of $\mathrm{NaCl}$ through irrigation water twice in a week. All the treatments were replicated three times in a completely randomized design.

\section{Treatments}

\section{Inoculants:}

T2 - Scutellospora calospora

T3 - TRY 1 (Acaulospora sp.)

T4 - TRY 2 (Scutellospora sp.)

T5 - TRY 3 (Glomus sp.)

T6 - TFS 1 (Glomus sp.)

$\mathrm{T} 7$ - Control ( $\mathrm{NaCl}$ alone)

\section{Salinity Levels}
$\mathrm{L} 1-1.5 \mathrm{dSm}^{-1}$
$\mathrm{L} 2-3.0 \mathrm{dSm}^{-1}$
$\mathrm{L} 3-4.5 \mathrm{dSm}^{-1}$

\section{Observations}

\section{Analysis of plant nutrients}

The plant samples were collected at 45 DAS as well as at harvest and analysed for the nutrient contents in the plants. The methodologies followed are represented in table below. Standard methodologies for the analysis of plant samples

T1 - Glomus intraradices

\begin{tabular}{|c|l|l|l|l|}
\hline $\begin{array}{c}\text { S. } \\
\text { No. }\end{array}$ & \multicolumn{1}{|c|}{ Parameter } & \multicolumn{1}{|c|}{ Unit } & \multicolumn{1}{|c|}{ Method } & \multicolumn{1}{|c|}{ Reference } \\
\hline $\mathbf{1 .}$ & Total nitrogen & per cent & $\begin{array}{l}\text { Diacid extract (prepared by mixing } \mathrm{H}_{2} \mathrm{SO}_{4}: \mathrm{HClO}_{4} \\
\text { @ 5:2) - semi automatic Kjeldahl distillation } \\
\text { Triacid extract - Vanadomolybdate colorimetric } \\
\text { method }\end{array}$ & $\begin{array}{l}\text { Humphries } \\
\text { (1956) }\end{array}$ \\
\hline Jackson \\
2. & Total phosphorous & per cent & $\begin{array}{l}\text { Jackson } \\
\text { Triacid extract - Flame photometer }\end{array}$ \\
\hline 3. & Total potassium & per cent & (1973) \\
\hline 4. & Micronutrients & ppm & Triacid extract - Atomic Absorption Spectroscopy & $\begin{array}{l}\text { USEPA } \\
\text { (1979) }\end{array}$ \\
\hline $\mathbf{5 .}$ & Sodium & per cent & Triacid extract - Flame photometer & $\begin{array}{l}\text { Jackson } \\
\text { (1973) }\end{array}$ \\
\hline
\end{tabular}

\section{Computation of nutrient uptake}

Dry matter productions at different stages were recorded for each plant. The quantity of element taken by the plant was obtained by multiplying the dry weight with that of nutrient content.

\section{Statistical analysis}

The data were subjected to statistical analysis by variance $(\mathrm{P}=0.05)$ with mean separation by Least significant difference (LSD) as per the methods detailed by the Panse and Sukhatme (1978). The analysis for microbial population 
count was based on the log and arcsine transformed values.

\section{Results and Discussion}

\section{Nutrient uptake}

The status of nutrients in this study revealed that, uptake of nutrients significantly increased in mycorrhizal treatments but the uptake was found to decrease with increase in salt levels in all the treatments (Table 1). As like nitrogen uptake, phophorus uptake was also found to be higher at harvest. At harvest, there was an overall increase in uptake of phosphorus and the highest was in $G$. intraradices followed by $S$. calospora inoculation (Table 2). Table 3 shows the uptake of potassium with gradual decrease on salt increments, still with a steady increase with respect to growth stage where, the maximum was at harvest in $G$. intraradices followed by $S$. calospora (Fig. 1).

\section{Micronutrient uptake}

The micronutrient content was read in plant samples at 45 DAS and harvest while the uptake was higher at harvest. Mycorrhizal treatments influenced the uptake of iron, copper and zinc, among which, same significant difference was observed between the treatments. The uptake was maximum at L1 $\left(1.5 \mathrm{dSm}^{-1}\right)$ in all the treatments. $G$. intraradices showed the maximum of 14.51, 1.63 and $3.71 \mathrm{mg}^{-1 a n t^{-1}}$ of iron, copper and zinc respectively (Table $4 a, 4 b, 4 c$ ) but the latter was not significant within the interactions. With the increase in salt levels, all the nutrients were found to be decreased recording the least at $\mathrm{L} 3\left(4.5 \mathrm{dSm}^{-1}\right)$.

\section{Sodium}

Treatments with AM fungal inoculation showed comparatively reduced uptake of sodium than the control. The uptake of sodium was maximum at harvest and was found to be increased with increments in salt levels. All the treatments showed reduced uptake when compared to the control plants. Treatment with $G$. intraradices marked the least (17.26, 20.12 and $21.07 \mathrm{mg}$ plant $^{-1}$ at L1, L2 and L3 respectively) followed by $S$. calospora (18.26, 20.35 and $21.33 \mathrm{mg} \mathrm{plant}^{-1}$ at L1, L2 and L3 respectively) (Table 5).

\section{Available nutrient status on soil}

The available nitrogen content in soil was analysed at two stages of crop growth and the treatments showed significant increase at both stages when compared to control. At L1 (1.5 $\mathrm{dSm}^{-1}$ ), treatments inoculated with $S$. calospora and $G$. intraradices recorded the highest of 249.0 and $248.0 \mathrm{~kg} \mathrm{ha}^{-1}$ (Table 6). The availability of phosphorus was significantly influenced by AM fungal inoculation in each level of salt than in control. Treatments with $G$. intraradices and S. calospora showed availability of 17.30 and $16.40 \mathrm{~kg} \mathrm{P} \mathrm{ha}^{-1}$ (with 63.8 and 61.0 per cent increase over control respectively) (Table 7). Mycorrhizal inoculation significantly influenced the availability of potassium but it was not significant with respect the salt levels and interactions. Among the treatments, $G$. intraradices ranked high with $165.0 \mathrm{~kg} \mathrm{~K} \mathrm{ha}^{-1}$ followed by $S$. calospora with $164.0 \mathrm{~kg} \mathrm{~K} \mathrm{ha}^{-1}$ at L1 (1.5 $\left.\mathrm{dSm}^{-1}\right)$ (Table 8).

\section{Available micronutrient contents}

The soil micronutrient contents were found to be decreased with increase in salt levels as well as with stages of plant growth and the nutrient availability were statistically non significant under the interaction between the treatmens and salt levels. Among the three salt levels, soils with L1 $\left(1.5 \mathrm{dSm}^{-1}\right)$ accumulated higher micronutrients both at 45 DAS and at harvest. 
Table.1 Effect of AM fungal isolates on nitrogen uptake in Onion against various levels of salinity

\begin{tabular}{|c|c|c|c|c|c|c|c|c|c|c|c|}
\hline \multirow[t]{3}{*}{ S.No } & \multirow[t]{3}{*}{ Treatments } & \multicolumn{10}{|c|}{ Nitrogen uptake $\left(\mathrm{mg} \mathrm{plant}^{-1}\right)$} \\
\hline & & \multicolumn{3}{|c|}{45 DAS } & \multirow[t]{2}{*}{ Mean } & \multirow{2}{*}{$\begin{array}{c}\text { Per cent } \\
\text { increase } \\
\text { over } \\
\text { control }\end{array}$} & \multicolumn{3}{|c|}{ At harvest } & \multirow[t]{2}{*}{ Mean } & \multirow{2}{*}{$\begin{array}{c}\text { Per cent } \\
\text { increase } \\
\text { over } \\
\text { control }\end{array}$} \\
\hline & & L1 & L2 & $\mathbf{L 3}$ & & & L1 & L2 & $\mathbf{L 3}$ & & \\
\hline 1. & G. intraradices & $\begin{array}{l}20.13 \\
(178)\end{array}$ & $\begin{array}{c}15.78 \\
(222.0)\end{array}$ & $\begin{array}{c}13.48 \\
(378.0)\end{array}$ & 16.46 & 230.6 & $\begin{array}{c}56.31 \\
(160.45)\end{array}$ & $\begin{array}{c}50.15 \\
(178.3)\end{array}$ & $\begin{array}{c}43.48 \\
(205.5)\end{array}$ & 49.98 & 178.3 \\
\hline 2. & S. calospora & $\begin{array}{c}20.03 \\
(177.4)\end{array}$ & $\begin{array}{c}15.68 \\
(220.0)\end{array}$ & $\begin{array}{c}12.01 \\
(325.8)\end{array}$ & 15.91 & 219.4 & $\begin{array}{c}53.96 \\
(149.5)\end{array}$ & $\begin{array}{c}46.35 \\
(157.2)\end{array}$ & $\begin{array}{c}43.16 \\
(203.3)\end{array}$ & 47.82 & 166.3 \\
\hline 3. & TRY 1 & 12.50 & 9.76 & 6.52 & 9.59 & 92.6 & 37.91 & 34.26 & 29.77 & 33.98 & 89.2 \\
\hline 4. & TRY 2 & 11.83 & 8.11 & 7.30 & 9.08 & 82.3 & 42.93 & 39.43 & 32.58 & 38.31 & 113.3 \\
\hline 5. & TRY 3 & $\begin{array}{c}15.82 \\
(119.1)\end{array}$ & $\begin{array}{c}12.62 \\
(157.5)\end{array}$ & $\begin{array}{c}10.87 \\
(285.4)\end{array}$ & 13.10 & 163.1 & $\begin{array}{c}47.80 \\
(121.0)\end{array}$ & $\begin{array}{c}43.8 \\
(143.0)\end{array}$ & $\begin{array}{c}39.28 \\
(176.0)\end{array}$ & 43.62 & 142.9 \\
\hline 6. & TFS 1 & 11.42 & 8.90 & 7.10 & 9.14 & 83.5 & 40.57 & 37.58 & 30.65 & 36.27 & 101.9 \\
\hline \multirow[t]{4}{*}{7.} & Control & 7.22 & 4. 90 & 2.82 & 4.98 & - & 21.62 & 18.02 & 14.23 & 17.96 & - \\
\hline & Mean & 14.14 & 10.82 & 8.59 & 11.18 & & 43.01 & 38.51 & 33.31 & 38.28 & \\
\hline & & \multicolumn{2}{|c|}{ SEd } & \multicolumn{2}{|c|}{ CD (0.05) } & & \multicolumn{2}{|l|}{ SEd } & \multicolumn{2}{|c|}{ CD (0.05) } & \\
\hline & $\begin{array}{c}\mathbf{T} \\
\mathbf{L} \\
\mathbf{T} \times \mathbf{L}\end{array}$ & \multicolumn{2}{|c|}{$\begin{array}{l}0.23 \\
0.15 \\
0.41 \\
\end{array}$} & \multicolumn{2}{|c|}{$\begin{array}{l}0.48 \\
0.31 \\
0.83 \\
\end{array}$} & & \multicolumn{2}{|c|}{$\begin{array}{l}0.57 \\
0.37 \\
0.98 \\
\end{array}$} & \multicolumn{2}{|c|}{$\begin{array}{l}1.15 \\
0.75 \\
1.99 \\
\end{array}$} & \\
\hline
\end{tabular}

Values represent mean of three replicates $\mathrm{L} 1-1.5 \mathrm{dSm}^{-1} ; \mathrm{L}^{2}-3.0 \mathrm{dSm}^{-1} ; \mathrm{L} 3-4.5 \mathrm{dSm}^{-1}$

DAS - Days after sowing, Value in paranthesis indicate per cent increase over control

G. intraradices - Glomus intraradices

S. calospora - Scutellospora calospora

TRY 1-Acaulospora sp

TRY 3- Glomus mosseae

TRY 2- Scutellospora sp.

TFS 1- Glomus aggregatum 
Table.2 Effect of AM fungal isolates on phosphorus uptake in Onion against various levels of salinity

\begin{tabular}{|c|c|c|c|c|c|c|c|c|c|c|c|}
\hline \multirow[t]{3}{*}{ S.No } & \multirow[t]{3}{*}{ Treatments } & \multicolumn{10}{|c|}{ Phosphorus uptake (mg plant ${ }^{-1}$ ) } \\
\hline & & \multicolumn{3}{|c|}{45 DAS } & \multirow[t]{2}{*}{ Mean } & \multirow{2}{*}{$\begin{array}{l}\text { Per cent } \\
\text { increase } \\
\text { over } \\
\text { control }\end{array}$} & \multicolumn{3}{|c|}{ At harvest } & \multirow[t]{2}{*}{ Mean } & \multirow{2}{*}{$\begin{array}{c}\text { Per cent } \\
\text { increase } \\
\text { over } \\
\text { control }\end{array}$} \\
\hline & & $\mathbf{L 1}$ & L2 & $\mathbf{L 3}$ & & & L1 & L2 & $\mathbf{L 3}$ & & \\
\hline 1. & G. intraradices & $\begin{array}{c}7.24 \\
(128.4)\end{array}$ & $\begin{array}{c}6.27 \\
(134.0)\end{array}$ & $\begin{array}{c}6.04 \\
(178.3)\end{array}$ & 6.52 & 144.1 & $\begin{array}{c}19.70 \\
(81.47)\end{array}$ & $\begin{array}{c}18.94 \\
(101.5)\end{array}$ & $\begin{array}{c}17.88 \\
(128.3)\end{array}$ & 18.84 & 101.2 \\
\hline 2. & S. calospora & $\begin{array}{c}6.85 \\
(116.1)\end{array}$ & $\begin{array}{c}6.34 \\
(136.6)\end{array}$ & $\begin{array}{c}5.16 \\
(137.8)\end{array}$ & 6.12 & 129.1 & $\begin{array}{c}17.11 \\
(57.70)\end{array}$ & $\begin{array}{c}17.25 \\
(83.5)\end{array}$ & $\begin{array}{c}16.85 \\
(115.2)\end{array}$ & 17.07 & 82.4 \\
\hline 3. & TRY 1 & 4.52 & 4.15 & 3.48 & 4.05 & 51.7 & $\begin{array}{c}15.01 \\
(3.34)\end{array}$ & 13.33 & 11.27 & 13.20 & 41.1 \\
\hline 4. & TRY 2 & 3.51 & 3.15 & 3.92 & 3.53 & 32.1 & 13.56 & 11.71 & 10.92 & 12.06 & 28.9 \\
\hline 5. & TRY 3 & $\begin{array}{c}4.73 \\
(49.2)\end{array}$ & $\begin{array}{c}4.58 \\
(71.0)\end{array}$ & $\begin{array}{c}4.18 \\
(92.6)\end{array}$ & 4.50 & 68.4 & 14.27 & $\begin{array}{l}13.82 \\
(47.0)\end{array}$ & $\begin{array}{l}11.48 \\
(46.6)\end{array}$ & 13.19 & 40.9 \\
\hline 6. & TFS 1 & 4.19 & 3.13 & 2.93 & 3.42 & 28.0 & 13.28 & 12.6 & 10.84 & 12.24 & 30.8 \\
\hline \multirow[t]{4}{*}{7.} & Control & 3.17 & 2.68 & 2.17 & 2.67 & - & 10.85 & 9.4 & 7.83 & 9.36 & - \\
\hline & \multirow[t]{2}{*}{ Mean } & 4.89 & 4.33 & 3.98 & 4.40 & & 14.82 & 13.86 & 12.44 & 13.70 & \\
\hline & & \multicolumn{2}{|l|}{ SEd } & \multicolumn{2}{|c|}{ CD (0.05) } & & \multicolumn{2}{|c|}{ SEd } & \multicolumn{2}{|c|}{ CD (0.05) } & \\
\hline & $\begin{array}{c}\mathbf{T} \\
\mathbf{L} \\
\mathbf{T} \times \mathbf{L}\end{array}$ & \multicolumn{2}{|c|}{$\begin{array}{l}\mathbf{0 . 0 7} \\
\mathbf{0 . 0 4} \\
\mathbf{0 . 1 2}\end{array}$} & \multicolumn{2}{|c|}{$\begin{array}{l}0.15 \\
0.09 \\
0.26\end{array}$} & & \multicolumn{2}{|c|}{$\begin{array}{l}0.16 \\
0.11 \\
0.29\end{array}$} & \multicolumn{2}{|c|}{$\begin{array}{l}0.34 \\
0.22 \\
0.58 \\
\end{array}$} & \\
\hline
\end{tabular}

Values represent mean of three replicates; $\mathrm{L} 1-1.5 \mathrm{dSm}^{-1} ; \mathrm{L}^{2}-3.0 \mathrm{dSm}^{-1} ; \mathrm{L} 3-4.5 \mathrm{dSm}^{-1}$

DAS - Days after sowing; Value in paranthesis indicate per cent increase over control

G. intraradices - Glomus intraradices

S. calospora - Scutellospora calospora

TRY 1- Acaulospora sp

TRY 3- Glomus mosseae

TRY 2- Scutellospora sp.

TFS 1- Glomus aggregatum 
Table.3 Effect of AM fungal isolates on potassium uptake in Onion against various levels of salinity

\begin{tabular}{|c|c|c|c|c|c|c|c|c|c|c|c|}
\hline \multirow[t]{3}{*}{ S.No } & \multirow[t]{3}{*}{ Treatments } & \multicolumn{10}{|c|}{ Potassium uptake (mg plant $\left.{ }^{-1}\right)$} \\
\hline & & \multicolumn{3}{|c|}{45 DAS } & \multirow[t]{2}{*}{ Mean } & \multirow{2}{*}{$\begin{array}{c}\text { Per cent } \\
\text { increase } \\
\text { over } \\
\text { control }\end{array}$} & \multicolumn{3}{|c|}{ At harvest } & \multirow[t]{2}{*}{ Mean } & \multirow{2}{*}{$\begin{array}{c}\text { Per cent } \\
\text { increase } \\
\text { over } \\
\text { control }\end{array}$} \\
\hline & & L1 & L2 & $\mathbf{L 3}$ & & & L1 & L2 & $\mathbf{L 3}$ & & \\
\hline 1. & G. intraradices & $\begin{array}{c}43.95 \\
(207.1)\end{array}$ & $\begin{array}{c}34.81 \\
(246.7)\end{array}$ & $\begin{array}{c}29.8 \\
(398.3)\end{array}$ & 36.19 & 257.9 & $\begin{array}{c}88.12 \\
(405.3)\end{array}$ & $\begin{array}{c}78.32 \\
(471.2)\end{array}$ & $\begin{array}{c}68.48 \\
(434.1)\end{array}$ & 78.31 & 434.2 \\
\hline 2. & S. calospora & $\begin{array}{c}39.31 \\
(174.7)\end{array}$ & $\begin{array}{c}32.97 \\
(228.4)\end{array}$ & $\begin{array}{c}25.21 \\
(321.6)\end{array}$ & 32.50 & 221.4 & $\begin{array}{c}84.86 \\
(386.6)\end{array}$ & $\begin{array}{c}74.38 \\
(442.5)\end{array}$ & $\begin{array}{c}64.33 \\
(401.8)\end{array}$ & 74.52 & 408.3 \\
\hline 3. & TRY 1 & 23.24 & 18.17 & 12.4 & 17.94 & 77.4 & 50.22 & 46.67 & 40.85 & 45.91 & 213.2 \\
\hline 4. & TRY 2 & 22.02 & 15.6 & 14.25 & 17.29 & 71.0 & 53.66 & 49.78 & 41.35 & 48.26 & 229.2 \\
\hline 5. & TRY 3 & $\begin{array}{c}28.73 \\
(100.7)\end{array}$ & $\begin{array}{c}24.31 \\
(142.1)\end{array}$ & $\begin{array}{c}21.32 \\
(256.5)\end{array}$ & 24.79 & 145.2 & $\begin{array}{c}60.02 \\
(244.1)\end{array}$ & $\begin{array}{c}54.85 \\
(300.0)\end{array}$ & $\begin{array}{c}48.07 \\
(275.0)\end{array}$ & 54.31 & 270.5 \\
\hline 6. & TFS 1 & 19.38 & 15.64 & 13.06 & 16.03 & 58.5 & 50.51 & 35.38 & 23.17 & 36.35 & 148.0 \\
\hline \multirow[t]{4}{*}{7.} & Control & 14.31 & 10.04 & 5.98 & 10.11 & - & 17.44 & 13.71 & 12.82 & 14.66 & - \\
\hline & Mean & 27.28 & 21.65 & 17.43 & 22.12 & & 57.83 & 50.44 & 42.72 & 50.33 & \\
\hline & & \multicolumn{2}{|l|}{ SEd } & \multicolumn{2}{|c|}{ CD $(0.05)$} & & \multicolumn{2}{|c|}{ SEd } & \multicolumn{2}{|c|}{ CD $(0.05)$} & \\
\hline & $\begin{array}{c}\mathbf{T} \\
\mathbf{L} \\
\mathbf{T} \times \mathbf{L}\end{array}$ & \multicolumn{2}{|c|}{$\begin{array}{l}0.51 \\
0.33 \\
0.89\end{array}$} & \multicolumn{2}{|c|}{$\begin{array}{l}1.04 \\
0.68 \\
1.80\end{array}$} & & \multicolumn{2}{|c|}{$\begin{array}{l}1.13 \\
0.74 \\
1.96\end{array}$} & \multicolumn{2}{|c|}{$\begin{array}{l}2.29 \\
1.50 \\
3.97\end{array}$} & \\
\hline
\end{tabular}

Values represent mean of three replicates; $\mathrm{L} 1-1.5 \mathrm{dSm}^{-1} ; \mathrm{L}^{2}-3.0 \mathrm{dSm}^{-1} ; \mathrm{L} 3-4.5 \mathrm{dSm}^{-1}$

DAS - Days after sowing; Value in paranthesis indicate per cent increase over control

G. intraradices - Glomus intraradices

S. calospora - Scutellospora calospora

TRY 1- Acaulospora sp

TRY 3- Glomus mosseae

TRY 2- Scutellospora sp.

TFS 1- Glomus aggregatum 
Table.4a Effect of AM fungal isolates on iron uptake in Onion against various levels of salinity

\begin{tabular}{|c|c|c|c|c|c|c|c|c|c|}
\hline \multirow[t]{3}{*}{ S.No } & \multirow[t]{3}{*}{ Treatments } & \multicolumn{8}{|c|}{ Iron uptake (mg plant ${ }^{-1}$ ) } \\
\hline & & \multicolumn{3}{|c|}{45 DAS } & \multirow[t]{2}{*}{ Mean } & \multicolumn{3}{|c|}{ At harvest } & \multirow[t]{2}{*}{ Mean } \\
\hline & & L1 & $\mathbf{L 2}$ & $\mathbf{L 3}$ & & L1 & $\mathbf{L 2}$ & $\mathbf{L 3}$ & \\
\hline 1. & G. intraradices & 11.90 & 8.84 & 5.70 & 8.81 & 14.51 & 12.24 & 8.33 & 11.70 \\
\hline 2. & S. calospora & 11.91 & 7.68 & 5.30 & 8.30 & 13.70 & 10.87 & 8.40 & 11.00 \\
\hline 3. & TRY 1 & 10.17 & 7.22 & 4.48 & 7.29 & 10.94 & 7.52 & 6.24 & 8.23 \\
\hline 4. & TRY 2 & 10.23 & 7.25 & 4.57 & 7.35 & 12.59 & 7.47 & 6.15 & 8.74 \\
\hline 5. & TRY 3 & 10.50 & 7.64 & 4.77 & 7.64 & 14.83 & 9.35 & 6.58 & 10.25 \\
\hline 6. & TFS 1 & 9.42 & 6.94 & 4.38 & 6.91 & 12.09 & 7.90 & 5.54 & 8.51 \\
\hline \multirow[t]{6}{*}{7.} & Control & 9.11 & 5.68 & 4.08 & 6.29 & 10.68 & 7.92 & 5.07 & 7.89 \\
\hline & Mean & 10.46 & 7.32 & 4.75 & 7.51 & 12.76 & 9.04 & 6.62 & 9.47 \\
\hline & & \multicolumn{2}{|c|}{ SEd } & \multicolumn{2}{|c|}{ CD (0.05) } & \multicolumn{2}{|l|}{ SEd } & \multicolumn{2}{|c|}{ CD (0.05) } \\
\hline & $\mathbf{T}$ & \multicolumn{2}{|c|}{0.127} & \multicolumn{2}{|c|}{0.256} & \multicolumn{2}{|c|}{0.160} & \multicolumn{2}{|c|}{0.323} \\
\hline & $\mathbf{L}$ & \multicolumn{2}{|c|}{0.083} & \multicolumn{2}{|c|}{0.168} & \multicolumn{2}{|c|}{0.104} & \multicolumn{2}{|c|}{0.211} \\
\hline & $\mathbf{T} \times \mathbf{L}$ & \multicolumn{2}{|c|}{0.220} & \multicolumn{2}{|c|}{0.444} & \multicolumn{2}{|c|}{0.277} & \multicolumn{2}{|c|}{0.560} \\
\hline
\end{tabular}

$\mathrm{L} 1-1.5 \mathrm{dSm}^{-1} ; \mathrm{L} 2-3.0 \mathrm{dSm}^{-1} ; \mathrm{L} 3-4.5 \mathrm{dSm}^{-1}$; DAS - Days after sowing Values represent mean of three replicates; Value in paranthesis indicate per cent increase over control

G. intraradices - Glomus intraradices

S. calospora - Scutellospora calospora

TRY 1-Acaulospora sp

TRY 3- Glomus mosseae

TRY 2-Scutellospora sp.

TFS 1- Glomus aggregatum 
Table.4b Effect of AM fungal isolates on copper uptake in Onion against various levels of salinity

\begin{tabular}{|c|c|c|c|c|c|c|c|c|c|}
\hline \multirow[t]{3}{*}{ S.No. } & \multirow[t]{3}{*}{ Treatments } & \multicolumn{8}{|c|}{ Copper uptake (mg plant ${ }^{-1}$ ) } \\
\hline & & \multicolumn{3}{|c|}{45 DAS } & \multirow[t]{2}{*}{ Mean } & \multicolumn{3}{|c|}{ At harvest } & \multirow[t]{2}{*}{ Mean } \\
\hline & & L1 & $\mathbf{L 2}$ & L3 & & $\mathbf{L 1}$ & $\mathbf{L 2}$ & $\mathbf{L 3}$ & \\
\hline 1. & G. intraradices & 0.68 & 0.48 & 0.23 & 0.46 & 1.63 & 1.10 & 0.43 & 1.05 \\
\hline 2. & S. calospora & 0.64 & 0.45 & 0.24 & 0.44 & 1.51 & 1.05 & 0.43 & 1.00 \\
\hline 3. & TRY 1 & 0.34 & 0.39 & 0.20 & 0.31 & 1.54 & 0.93 & 0.30 & 0.92 \\
\hline 4. & TRY 2 & 0.33 & 0.38 & 0.21 & 0.31 & 1.54 & 0.98 & 0.30 & 0.94 \\
\hline 5. & TRY 3 & 0.42 & 0.38 & 0.19 & 0.33 & 1.54 & 0.98 & 0.38 & 0.97 \\
\hline 6. & TFS 1 & 0.38 & 0.30 & 0.17 & 0.28 & 1.59 & 1.05 & 0.28 & 0.97 \\
\hline \multirow[t]{6}{*}{7.} & Control & 0.34 & 0.30 & 0.17 & 0.27 & 1.45 & 0.85 & 0.22 & 0.84 \\
\hline & Mean & 0.45 & 0.38 & 0.20 & 0.34 & 1.54 & 0.99 & 0.33 & 0.96 \\
\hline & & \multicolumn{2}{|c|}{ SEd } & \multicolumn{2}{|c|}{ CD (0.05) } & \multicolumn{2}{|l|}{ SEd } & \multicolumn{2}{|c|}{ CD (0.05) } \\
\hline & $\mathbf{T}$ & \multicolumn{2}{|c|}{0.006} & \multicolumn{2}{|c|}{0.012} & \multicolumn{2}{|c|}{0.018} & \multicolumn{2}{|c|}{0.036} \\
\hline & $\mathbf{L}$ & \multicolumn{2}{|c|}{0.004} & \multicolumn{2}{|c|}{0.008} & \multicolumn{2}{|c|}{0.011} & \multicolumn{2}{|c|}{0.023} \\
\hline & $\mathbf{T} \times \mathbf{L}$ & \multicolumn{2}{|c|}{0.011} & \multicolumn{2}{|c|}{0.022} & \multicolumn{2}{|c|}{0.031} & \multicolumn{2}{|c|}{0.063} \\
\hline
\end{tabular}

Values represent mean of three replicates; $\mathrm{L} 1-1.5 \mathrm{dSm}^{-1} ; \mathrm{L} 2-3.0 \mathrm{dSm}^{-1} ; \mathrm{L} 3-4.5 \mathrm{dSm}^{-1}$, DAS - Days after sowing

Value in paranthesis indicate per cent increase over control

G. intraradices - Glomus intraradices

S. calospora - Scutellospora calospora

TRY 1-Acaulospora sp

TRY 3- Glomus mosseae

TRY 2- Scutellospora sp.

TFS 1- Glomus aggregatum 
Table.4c Effect of AM fungal isolates on zinc uptake in Onion against various levels of salinity

\begin{tabular}{|c|c|c|c|c|c|c|c|c|c|}
\hline \multirow[t]{3}{*}{ S.No. } & \multirow[t]{3}{*}{ Treatments } & \multicolumn{8}{|c|}{ Zinc uptake (mg plant ${ }^{-1}$ ) } \\
\hline & & \multicolumn{3}{|c|}{45 DAS } & \multirow[t]{2}{*}{ Mean } & \multicolumn{3}{|c|}{ At harvest } & \multirow[t]{2}{*}{ Mean } \\
\hline & & $\mathbf{L 1}$ & $\mathbf{L 2}$ & $\mathbf{L 3}$ & & L1 & $\mathbf{L 2}$ & $\mathbf{L 3}$ & \\
\hline 1. & G. intraradices & 1.26 & 0.71 & 0.35 & 0.77 & 3.71 & 1.8 & 0.91 & 2.14 \\
\hline 2. & S. calospora & 1.22 & 0.67 & 0.33 & 0.74 & 3.57 & 1.6 & 0.98 & 2.05 \\
\hline 3. & TRY 1 & 1.2 & 0.65 & 0.3 & 0.72 & 2.44 & 1.31 & 0.58 & 1.44 \\
\hline 4. & TRY 2 & 1.15 & 0.63 & 0.3 & 0.69 & 2.68 & 1.37 & 0.55 & 1.53 \\
\hline 5. & TRY 3 & 1.2 & 0.65 & 0.31 & 0.72 & 3.13 & 1.57 & 0.82 & 1.84 \\
\hline 6. & TFS 1 & 1.22 & 0.66 & 0.32 & 0.73 & 2.69 & 1.38 & 0.68 & 1.58 \\
\hline \multirow[t]{6}{*}{7.} & Control & 1.2 & 0.6 & 0.25 & 0.68 & 1.12 & 0.5 & 0.32 & 0.65 \\
\hline & Mean & 1.21 & 0.65 & 0.31 & 0.72 & 2.76 & 1.36 & 0.69 & 1.61 \\
\hline & & \multicolumn{2}{|c|}{ SEd } & \multicolumn{2}{|c|}{ CD (0.05) } & \multicolumn{2}{|c|}{ SEd } & \multicolumn{2}{|c|}{ CD (0.05) } \\
\hline & $\mathbf{T}$ & \multicolumn{2}{|c|}{0.013} & \multicolumn{2}{|c|}{0.02} & \multicolumn{2}{|c|}{0.031} & \multicolumn{2}{|c|}{0.063} \\
\hline & $\mathbf{L}$ & \multicolumn{2}{|c|}{0.008} & \multicolumn{2}{|c|}{0.01} & \multicolumn{2}{|c|}{0.020} & \multicolumn{2}{|c|}{0.041} \\
\hline & $\mathbf{T} \times \mathbf{L}$ & \multicolumn{2}{|c|}{0.023} & \multicolumn{2}{|c|}{ NS } & \multicolumn{2}{|c|}{0.054} & \multicolumn{2}{|c|}{ NS } \\
\hline
\end{tabular}

$\mathrm{L} 1-1.5 \mathrm{dSm}^{-1} ; \mathrm{L} 2-3.0 \mathrm{dSm}^{-1} ; \mathrm{L} 3-4.5 \mathrm{dSm}^{-1}$; DAS - Days after sowing

Values represent mean of three replicates; Value in paranthesis indicate per cent increase over control

G. intraradices - Glomus intraradices

S. calospora-Scutellospora calospora

TRY 1- Acaulospora sp

TRY 3- Glomus mosseae

TRY 2- Scutellospora sp.

TFS 1- Glomus aggregatum 
Table.5 Effect of AM fungal isolates on sodium uptake in Onion against various levels of salinity

\begin{tabular}{|c|c|c|c|c|c|c|c|c|c|}
\hline \multirow[t]{3}{*}{ S.No. } & \multirow[t]{3}{*}{ Treatments } & \multicolumn{8}{|c|}{ Sodium uptake (mg plant ${ }^{-1}$ ) } \\
\hline & & \multicolumn{3}{|c|}{45 DAS } & Mean & \multicolumn{3}{|c|}{ At harvest } & \multirow[t]{2}{*}{ Mean } \\
\hline & & $\mathbf{L 1}$ & L2 & $\mathbf{L 3}$ & & L1 & $\mathbf{L 2}$ & $\mathbf{L 3}$ & \\
\hline 1. & G. intraradices & 12.02 & 13.47 & 17.18 & 14.22 & 17.26 & 20.12 & 21.07 & 19.48 \\
\hline 2. & S. calospora & 12.31 & 15.20 & 17.72 & 15.08 & 18.26 & 20.35 & 21.33 & 19.98 \\
\hline 3. & TRY 1 & 13.54 & 14.34 & 17.25 & 15.04 & 16.02 & 21.67 & 23.16 & 20.28 \\
\hline 4. & TRY 2 & 14.31 & 15.16 & 18.06 & 15.84 & 18.71 & 21.70 & 23.35 & 21.25 \\
\hline 5. & TRY 3 & 13.15 & 14.71 & 17.21 & 15.02 & 17.02 & 20.03 & 21.68 & 19.66 \\
\hline 6. & TFS 1 & 15.74 & 17.18 & 18.40 & 16.99 & 19.32 & 22.37 & 23.85 & 21.85 \\
\hline \multirow[t]{6}{*}{7.} & Control & 17.33 & 18.14 & 19.90 & 18.45 & 20.54 & 22.71 & 25.52 & 22.92 \\
\hline & Mean & 14.00 & 16.00 & 17.96 & 15.81 & 18.16 & 21.28 & 23.11 & 20.85 \\
\hline & & \multicolumn{2}{|c|}{ SEd } & \multicolumn{2}{|c|}{ CD (0.05) } & \multicolumn{2}{|c|}{ SEd } & \multicolumn{2}{|c|}{ CD (0.05) } \\
\hline & $\mathbf{T}$ & \multicolumn{2}{|c|}{0.115} & \multicolumn{2}{|c|}{0.233} & \multicolumn{2}{|c|}{0.125} & \multicolumn{2}{|c|}{0.253} \\
\hline & $\mathbf{L}$ & \multicolumn{2}{|c|}{0.075} & \multicolumn{2}{|c|}{0.152} & \multicolumn{2}{|c|}{0.082} & \multicolumn{2}{|c|}{0.165} \\
\hline & $\mathbf{T} \times \mathbf{L}$ & \multicolumn{2}{|c|}{0.199} & \multicolumn{2}{|c|}{0.403} & \multicolumn{2}{|c|}{0.216} & \multicolumn{2}{|c|}{0.438} \\
\hline
\end{tabular}

$\mathrm{L} 1-1.5 \mathrm{dSm}^{-1} ; \mathrm{L} 2-3.0 \mathrm{dSm}^{-1} ; \mathrm{L} 3-4.5 \mathrm{dSm}^{-1} \mathrm{DAS}$ - Days after sowing

Values represent mean of three replicates; Value in paranthesis indicate per cent increase over control

G. intraradices - Glomus intraradices

S. calospora - Scutellospora calospora

TRY 1-Acaulospora sp

TRY 3- Glomus mosseae

TRY 2- Scutellospora sp.

TFS 1- Glomus aggregatum 
Table.6 Effect of AM fungal isolates on available nitrogen in Onion rhizosphere against various levels of salinity

\begin{tabular}{|c|c|c|c|c|c|c|c|c|c|c|c|}
\hline \multirow[t]{3}{*}{ S.No. } & \multirow[t]{3}{*}{ Treatments } & \multicolumn{10}{|c|}{ Available Nitrogen $\left(\mathrm{kg} \mathrm{ha}^{-1}\right)$} \\
\hline & & \multicolumn{3}{|c|}{45 DAS } & \multirow[t]{2}{*}{ Mean } & \multirow{2}{*}{$\begin{array}{c}\text { Per cent } \\
\text { increase over } \\
\text { control }\end{array}$} & \multicolumn{3}{|c|}{ At harvest } & \multirow[t]{2}{*}{ Mean } & \multirow{2}{*}{$\begin{array}{c}\text { Per cent } \\
\text { increase } \\
\text { over control }\end{array}$} \\
\hline & & $\mathbf{L 1}$ & $\mathbf{L 2}$ & $\mathbf{L 3}$ & & & L1 & $\mathbf{L 2}$ & $\mathbf{L 3}$ & & \\
\hline 1. & G. intraradices & 248.0 & 243.0 & 240.0 & 243.7 & 4.3 & 235.0 & 231.0 & 226.0 & 230.7 & 5.2 \\
\hline 2. & Scutellospora sp. & 249.0 & 244.0 & 241.0 & 244.7 & 4.7 & 238.0 & 232.0 & 227.0 & 232.3 & 5.9 \\
\hline 3. & TRY 1 & 245.0 & 240.0 & 235.0 & 240.0 & 2.7 & 227.0 & 223.0 & 220.0 & 223.3 & 1.8 \\
\hline 4. & TRY 2 & 240.0 & 236.0 & 232.0 & 236.0 & 1.0 & 228.0 & 223.0 & 221.0 & 224.0 & 2.1 \\
\hline 5. & TRY 3 & 242.0 & 241.0 & 236.0 & 239.7 & 2.6 & 233.0 & 228.0 & 225.0 & 228.7 & 4.3 \\
\hline 6. & TFS 1 & 240.0 & 238.0 & 233.0 & 237.0 & 1.4 & 226.0 & 222.0 & 218.0 & 222.0 & 1.2 \\
\hline \multirow[t]{6}{*}{7.} & Control & 239.0 & 232.0 & 230.0 & 233.7 & 4.3 & 223.0 & 220.0 & 215.0 & 219.3 & 5.2 \\
\hline & Mean & 243.3 & 239.1 & 235.3 & 239.2 & & 230.0 & 225.6 & 221.7 & 225.8 & \\
\hline & & \multicolumn{2}{|c|}{ SEd } & \multicolumn{2}{|c|}{ CD (0.05) } & & \multicolumn{2}{|c|}{ SEd } & \multicolumn{2}{|c|}{ CD (0.05) } & \\
\hline & $\mathbf{T}$ & \multicolumn{2}{|c|}{0.266} & \multicolumn{2}{|c|}{0.539} & & \multicolumn{2}{|c|}{0.301} & \multicolumn{2}{|c|}{0.609} & \\
\hline & $\mathbf{L}$ & \multicolumn{2}{|c|}{0.174} & \multicolumn{2}{|c|}{0.353} & & \multicolumn{2}{|c|}{0.197} & \multicolumn{2}{|c|}{0.398} & \\
\hline & $\mathbf{T} \times \mathbf{L}$ & \multicolumn{2}{|c|}{0.462} & \multicolumn{2}{|c|}{0.934} & & \multicolumn{2}{|c|}{0.521} & \multicolumn{2}{|c|}{1.054} & \\
\hline
\end{tabular}

$\mathrm{L} 1-1.5 \mathrm{dSm}^{-1} ; \mathrm{L} 2-3.0 \mathrm{dSm}^{-1} ; \mathrm{L} 3-4.5 \mathrm{dSm}^{-1}$, DAS - Days after sowing

Values represent mean of three replicates; Value in paranthesis indicate per cent increase over control

G. intraradices - Glomus intraradices

S. calospora - Scutellospora calospora

TRY 1-Acaulospora sp

TRY 3-Glomus mosseae

TRY 2-Scutellospora sp.

TFS 1- Glomus aggregatum 
Table.7 Effect of AM fungal isolates on available phosphorus in Onion rhizosphere against various levels of salinity

\begin{tabular}{|c|c|c|c|c|c|c|c|c|c|c|c|}
\hline \multirow[t]{3}{*}{ S.No. } & \multirow[t]{3}{*}{ Treatments } & \multicolumn{10}{|c|}{ Available Phosphorus $\left(\mathrm{kg} \mathrm{ha}^{-1}\right)$} \\
\hline & & \multicolumn{3}{|c|}{45 DAS } & \multirow[t]{2}{*}{ Mean } & \multirow{2}{*}{$\begin{array}{c}\text { Per cent } \\
\text { increase over } \\
\text { control }\end{array}$} & \multicolumn{3}{|c|}{ At harvest } & \multirow[t]{2}{*}{ Mean } & \multirow{2}{*}{$\begin{array}{c}\text { Per cent } \\
\text { increase } \\
\text { over control }\end{array}$} \\
\hline & & L1 & $\mathbf{L} 2$ & $\mathbf{L 3}$ & & & $\mathbf{L 1}$ & $\mathbf{L 2}$ & L3 & & \\
\hline 1. & G. intraradices & $\begin{array}{l}17.30 \\
(73.0)\end{array}$ & $\begin{array}{l}15.50 \\
(58.1)\end{array}$ & $\begin{array}{l}13.40 \\
(57.6)\end{array}$ & 15.40 & 63.8 & $\begin{array}{c}16.10 \\
(96.3)\end{array}$ & $\begin{array}{l}13.60 \\
(70.0)\end{array}$ & $\begin{array}{l}12.60 \\
(75.0)\end{array}$ & 14.10 & 80.8 \\
\hline 2. & S. calospora & $\begin{array}{l}16.40 \\
(64.0)\end{array}$ & $\begin{array}{l}15.00 \\
(53.0)\end{array}$ & $\begin{array}{l}14.00 \\
(64.7)\end{array}$ & 15.13 & 61.0 & $\begin{array}{l}15.80 \\
(92.6)\end{array}$ & $\begin{array}{l}13.60 \\
(70.0)\end{array}$ & $\begin{array}{l}11.80 \\
(63.9)\end{array}$ & 13.73 & 76.1 \\
\hline 3. & TRY 1 & 12.30 & 11.10 & 10.60 & 11.33 & 20.6 & 10.40 & 10.00 & 15.60 & 12.00 & 53.8 \\
\hline 4. & TRY 2 & 12.30 & 11.80 & $\begin{array}{l}11.10 \\
(30.6)\end{array}$ & 11.73 & 24.8 & 10.50 & 10.00 & 9.80 & 10.10 & 29.5 \\
\hline 5. & TRY 3 & $\begin{array}{l}13.70 \\
(37.0)\end{array}$ & $\begin{array}{c}12.00 \\
(22.45)\end{array}$ & $\begin{array}{l}11.10 \\
(30.6)\end{array}$ & 12.26 & 30.5 & $\begin{array}{l}11.50 \\
(40.2)\end{array}$ & $\begin{array}{l}11.00 \\
(37.5)\end{array}$ & $\begin{array}{l}10.20 \\
(41.6)\end{array}$ & 10.90 & 39.7 \\
\hline 6. & TFS 1 & 11.90 & 10.20 & 9.80 & 10.63 & 13.1 & 9.50 & 8.20 & 7.50 & 8.40 & 7.7 \\
\hline \multirow[t]{4}{*}{7.} & Control & 10.00 & 9.80 & 8.50 & 9.43 & - & 8.20 & 8.00 & 7.20 & 7.80 & - \\
\hline & Mean & 13.41 & 12.20 & 11.21 & 12.27 & & 11.71 & 10.63 & 10.67 & 11.00 & \\
\hline & & \multicolumn{2}{|c|}{ SEd } & \multicolumn{2}{|c|}{ CD (0.05) } & & \multicolumn{2}{|c|}{ SEd } & \multicolumn{2}{|c|}{ CD (0.05) } & \\
\hline & $\begin{array}{c}\mathbf{T} \\
\mathbf{L} \\
\mathbf{T} \times \mathbf{L}\end{array}$ & & & & & & & & & & \\
\hline
\end{tabular}

$\mathrm{L} 1-1.5 \mathrm{dSm}^{-1} ; \mathrm{L} 2-3.0 \mathrm{dSm}^{-1} ; \mathrm{L} 3-4.5 \mathrm{dSm}^{-1}$, DAS - Days after sowing

Values represent mean of three replicates; Value in paranthesis indicate per cent increase over control 
Table.8 Effect of AM fungal isolates on available potassium content in Onion against various levels of salinity

\begin{tabular}{|c|c|c|c|c|c|c|c|c|c|c|c|}
\hline \multirow[t]{3}{*}{ S.No. } & \multirow[t]{3}{*}{ Treatments } & \multicolumn{10}{|c|}{ Available Potassium $\left(\mathrm{kg} \mathrm{ha}^{-1}\right)$} \\
\hline & & \multicolumn{3}{|c|}{45 DAS } & \multirow[t]{2}{*}{ Mean } & \multirow{2}{*}{$\begin{array}{c}\text { Per cent } \\
\text { Increase over } \\
\text { control }\end{array}$} & \multicolumn{3}{|c|}{ At harvest } & \multirow[t]{2}{*}{ Mean } & \multirow{2}{*}{$\begin{array}{c}\text { Per cent } \\
\text { increase over } \\
\text { control }\end{array}$} \\
\hline & & $\mathbf{L 1}$ & $\mathbf{L 2}$ & $\mathbf{L 3}$ & & & L1 & $\mathbf{L 2}$ & $\mathbf{L 3}$ & & \\
\hline 1. & G. intraradices & 165.0 & 161.0 & 156.0 & 160.7 & 5.0 & 155.0 & 151.0 & 146.0 & 150.7 & 3.7 \\
\hline 2. & S. calospora & 164.0 & 161.0 & 155.0 & 160.0 & 4.6 & 153.0 & 152.0 & 145.0 & 150.0 & 3.2 \\
\hline 3. & TRY 1 & 161.0 & 158.0 & 152.0 & 157.0 & 2.6 & 152.0 & 149.0 & 143.0 & 148.0 & 1.9 \\
\hline 4. & TRY 2 & 162.0 & 156.0 & 152.0 & 156.7 & 2.4 & 153.0 & 149.0 & 142.0 & 148.0 & 1.9 \\
\hline 5. & TRY 3 & 162.0 & 158.0 & 155.0 & 158.3 & 3.5 & 154.0 & 150.0 & 143.0 & 149.0 & 2.5 \\
\hline 6. & TFS 1 & 159.0 & 156.0 & 153.0 & 156.0 & 2.0 & 151.0 & 150.0 & 143.0 & 148.0 & 1.9 \\
\hline \multirow[t]{6}{*}{7.} & Control & 157.0 & 152.0 & 150.0 & 153.0 & 5.0 & 150.0 & 146.0 & 140.0 & 145.3 & 3.7 \\
\hline & Mean & 161.4 & 157.4 & 153.3 & 157.4 & & 152.6 & 149.6 & 143.1 & 148.4 & \\
\hline & & \multicolumn{2}{|c|}{ SEd } & \multicolumn{2}{|c|}{ CD (0.05) } & & \multicolumn{2}{|c|}{ SEd } & \multicolumn{2}{|c|}{ CD (0.05) } & \\
\hline & $\mathbf{T}$ & \multirow{2}{*}{\multicolumn{2}{|c|}{2.60}} & \multicolumn{2}{|c|}{5.27} & & \multicolumn{2}{|c|}{2.40} & \multicolumn{2}{|c|}{ NS } & \\
\hline & $\mathbf{L}$ & & & \multicolumn{2}{|l|}{ NS } & & \multicolumn{2}{|l|}{1.57} & \multicolumn{2}{|c|}{3.17} & \\
\hline & $\mathbf{T} \times \mathbf{L}$ & \multicolumn{2}{|c|}{4.52} & \multicolumn{2}{|c|}{ NS } & & \multicolumn{2}{|c|}{4.16} & \multicolumn{2}{|c|}{ NS } & \\
\hline
\end{tabular}

$\mathrm{L} 1-1.5 \mathrm{dSm}^{-1} ; \mathrm{L} 2-3.0 \mathrm{dSm}^{-1} ; \mathrm{L} 3-4.5 \mathrm{dSm}^{-1}$, DAS - Days after sowing

Values represent mean of three replicates; Value in paranthesis indicate per cent increase over control, NS - not significant

G. intraradices - Glomus intraradices

S. calospora - Scutellospora calospora

TRY 1- Acaulospora sp

TRY 3- Glomus mosseae

TRY 2- Scutellospora sp.

TFS 1- Glomus aggregatum 
Table.9a Effect of AM fungal isolates on micronutrient (iron) availability in rhizosphere soil of Onion against various levels of salinity

\begin{tabular}{|c|c|c|c|c|c|c|c|c|c|}
\hline \multirow[t]{3}{*}{ S. No. } & \multirow[t]{3}{*}{ Treatments } & \multicolumn{8}{|c|}{ Iron content (ppm) } \\
\hline & & \multicolumn{4}{|c|}{45 DAS } & \multicolumn{4}{|c|}{ At harvest } \\
\hline & & $\mathbf{L 1}$ & $\mathbf{L 2}$ & $\mathbf{L 3}$ & Mean & L1 & $\mathbf{L 2}$ & $\mathbf{L 3}$ & Mean \\
\hline 1. & G. intraradices & 6.10 & 5.45 & 5.12 & $\begin{array}{c}5.56 \\
(25.7)\end{array}$ & 6.00 & 5.24 & 4.85 & 5.36 \\
\hline 2. & S. calospora & 6.17 & 5.34 & 5.21 & $\begin{array}{c}5.57 \\
(26.1)\end{array}$ & 5.98 & 5.14 & 5.01 & 5.38 \\
\hline 3. & TRY 1 & 5.64 & 5.20 & 4.84 & $\begin{array}{c}5.23 \\
(18.3)\end{array}$ & 5.50 & 5.04 & 4.55 & 5.03 \\
\hline 4. & TRY 2 & 5.75 & 4.93 & 4.65 & $\begin{array}{c}5.11 \\
(15.6)\end{array}$ & 5.68 & 5.10 & 4.63 & 5.14 \\
\hline 5. & TRY 3 & 5.81 & 5.36 & 4.65 & $\begin{array}{c}5.27 \\
(19.3)\end{array}$ & 5.72 & 5.16 & 4.50 & 5.13 \\
\hline 6. & TFS 1 & 5.48 & 4.74 & 4.21 & $\begin{array}{l}4.81 \\
(8.8)\end{array}$ & 5.56 & 5.03 & 4.10 & 4.90 \\
\hline \multirow[t]{4}{*}{7.} & Control & 5.16 & 4.43 & 3.67 & 4.42 & 4.33 & 4.05 & 3.40 & 3.93 \\
\hline & Mean & 5.73 & 5.06 & 4.62 & 5.14 & 5.54 & 4.97 & 4.43 & 4.98 \\
\hline & & \multicolumn{2}{|c|}{ SEd } & \multicolumn{2}{|c|}{ CD (0.05) } & \multicolumn{2}{|c|}{ SEd } & \multicolumn{2}{|c|}{ CD $(0.05)$} \\
\hline & $\begin{array}{c}\mathbf{T} \\
\mathbf{L} \\
\mathbf{T x L}\end{array}$ & \multicolumn{2}{|c|}{$\begin{array}{l}0.03 \\
0.02 \\
0.05\end{array}$} & \multicolumn{2}{|c|}{$\begin{array}{c}0.06 \\
0.04 \\
\text { NS }\end{array}$} & \multicolumn{2}{|c|}{$\begin{array}{l}0.03 \\
0.02 \\
0.06\end{array}$} & \multicolumn{2}{|c|}{$\begin{array}{c}\mathbf{0 . 0 7} \\
\mathbf{0 . 0 4} \\
\text { NS }\end{array}$} \\
\hline
\end{tabular}

$\mathrm{L} 1-1.5 \mathrm{dSm}^{-1} ; \mathrm{L} 2-3.0 \mathrm{dSm}^{-1} ; \mathrm{L} 3-4.5 \mathrm{dSm}^{-1}$; DAS - Days after sowing; Values represent mean of three replicates

Values in parenthesis represent per cent increase over control; NS - not significant

G. intraradices - Glomus intraradices

S. calospora-Scutellospora calospora

TRY 1- Acaulospora sp

TRY 3- Glomus mosseae

TRY 2- Scutellospora sp.

TFS 1- Glomus aggregatum 
Table.9b Effect of AM fungal isolates on micronutrient (copper) availability in rhizosphere soil of Onion against various levels of salinity

\begin{tabular}{|c|c|c|c|c|c|c|c|c|c|}
\hline \multirow[t]{3}{*}{ S.No. } & \multirow[t]{3}{*}{ Treatments } & \multicolumn{8}{|c|}{ Copper content (ppm) } \\
\hline & & \multicolumn{3}{|c|}{45 DAS } & \multirow[t]{2}{*}{ Mean } & \multicolumn{3}{|c|}{ At harvest } & \multirow[t]{2}{*}{ Mean } \\
\hline & & L1 & L2 & $\mathbf{L 3}$ & & L1 & $\mathbf{L} 2$ & L3 & \\
\hline 1. & G. intraradices & 0.40 & 0.28 & 0.18 & $\begin{array}{c}0.29 \\
(43.3)\end{array}$ & 0.36 & 0.25 & 0.13 & $\begin{array}{c}0.25 \\
(54.2)\end{array}$ \\
\hline 2. & S. calospora & 0.40 & 0.30 & 0.19 & $\begin{array}{c}0.30 \\
(48.3)\end{array}$ & 0.36 & 0.28 & 0.15 & $\begin{array}{c}0.26 \\
(64.6)\end{array}$ \\
\hline 3. & TRY 1 & 0.30 & 0.22 & 0.15 & $\begin{array}{c}0.22 \\
(11.7)\end{array}$ & 0.28 & 0.20 & 0.10 & $\begin{array}{c}0.19 \\
(20.8)\end{array}$ \\
\hline 4. & TRY 2 & 0.30 & 0.22 & 0.16 & $\begin{array}{c}0.23 \\
(13.3)\end{array}$ & 0.29 & 0.20 & 0.11 & $\begin{array}{c}0.20 \\
(25.0)\end{array}$ \\
\hline 5. & TRY 3 & 0.31 & 0.24 & 0.16 & $\begin{array}{c}0.24 \\
(18.3)\end{array}$ & 0.26 & 0.20 & 0.10 & $\begin{array}{c}0.19 \\
(16.7)\end{array}$ \\
\hline 6. & TFS 1 & 0.28 & 0.22 & 0.15 & $\begin{array}{l}0.22 \\
(8.3)\end{array}$ & 0.25 & 0.21 & 0.06 & $\begin{array}{l}0.17 \\
(8.3)\end{array}$ \\
\hline \multirow[t]{4}{*}{7.} & Control & 0.25 & 0.20 & 0.15 & 0.20 & 0.21 & 0.20 & 0.06 & 0.16 \\
\hline & Mean & 0.32 & 0.24 & 0.16 & 0.24 & 0.29 & 0.22 & 0.10 & 0.20 \\
\hline & & \multicolumn{2}{|c|}{ SEd } & \multicolumn{2}{|c|}{ CD (0.05) } & \multicolumn{2}{|c|}{ SEd } & \multicolumn{2}{|c|}{ CD (0.05) } \\
\hline & $\begin{array}{c}\mathbf{T} \\
\mathbf{L} \\
\mathbf{T} \times \mathbf{L}\end{array}$ & \multicolumn{2}{|c|}{$\begin{array}{l}0.003 \\
0.002 \\
0.005\end{array}$} & \multicolumn{2}{|c|}{$\begin{array}{c}0.006 \\
0.004 \\
\text { NS }\end{array}$} & \multicolumn{2}{|c|}{$\begin{array}{l}0.004 \\
0.003 \\
0.008\end{array}$} & \multicolumn{2}{|c|}{$\begin{array}{c}0.009 \\
0.006 \\
\text { NS }\end{array}$} \\
\hline
\end{tabular}

$\mathrm{L} 1-1.5 \mathrm{dSm}^{-1}$; L2 - $3.0 \mathrm{dSm}^{-1}$; $\mathrm{L} 3-4.5 \mathrm{dSm}^{-1}$; DAS - Days after sowing

Values represent mean of three replicates; Value in paranthesis indicate per cent increase over control; NS - not significant
G. intraradices - Glomus intraradices
TRY 1- Acaulospora sp
S. calospora - Scutellospora calospora
TRY 2- Scutellospora sp.
TFS $1-$ Glon 
Table.9c Effect of AM fungal isolates on micronutrient (Zinc) availability in rhizosphere soil of Onion against various levels of salinity

\begin{tabular}{|c|c|c|c|c|c|c|c|c|c|}
\hline \multirow[t]{3}{*}{ S.No } & \multirow[t]{3}{*}{ Treatments } & \multicolumn{8}{|c|}{ Zinc content (ppm) } \\
\hline & & \multicolumn{3}{|c|}{45 DAS } & \multirow[t]{2}{*}{ Mean } & \multicolumn{3}{|c|}{ At harvest } & \multirow[t]{2}{*}{ Mean } \\
\hline & & L1 & $\mathbf{L 2}$ & L3 & & L1 & $\mathbf{L 2}$ & $\mathbf{L 3}$ & \\
\hline 1. & G. intraradices & 2.68 & 2.55 & 2.35 & $\begin{array}{c}2.53 \\
(63.0)\end{array}$ & 2.60 & 2.24 & 1.84 & $\begin{array}{c}2.23 \\
(72.6)\end{array}$ \\
\hline 2. & S. calospora & 2.66 & 2.34 & 2.20 & $\begin{array}{c}2.40 \\
(54.8)\end{array}$ & 2.58 & 2.16 & 1.90 & $\begin{array}{c}2.21 \\
(71.6)\end{array}$ \\
\hline 3. & TRY 1 & 2.48 & 2.20 & 2.01 & $\begin{array}{c}2.23 \\
(43.9)\end{array}$ & 2.31 & 2.00 & 1.53 & $\begin{array}{c}1.95 \\
(50.9)\end{array}$ \\
\hline 4. & TRY 2 & 2.60 & 2.22 & 1.95 & $\begin{array}{c}2.26 \\
(45.6)\end{array}$ & 2.52 & 1.94 & 1.66 & $\begin{array}{c}2.04 \\
(58.1)\end{array}$ \\
\hline 5. & TRY 3 & 2.64 & 2.35 & 1.95 & $\begin{array}{c}2.31 \\
(49.2)\end{array}$ & 2.56 & 2.15 & 1.70 & $\begin{array}{c}2.14 \\
(65.6)\end{array}$ \\
\hline 6. & TFS 1 & 2.40 & 2.11 & 1.74 & $\begin{array}{c}2.08 \\
(34.4)\end{array}$ & 2.20 & 2.01 & 1.20 & $\begin{array}{c}1.80 \\
(39.8)\end{array}$ \\
\hline \multirow[t]{4}{*}{7.} & Control & 2.07 & 1.57 & 1.01 & 1.55 & 1.76 & 1.27 & 0.83 & 1.29 \\
\hline & Mean & 2.50 & 2.19 & 1.89 & 2.19 & 2.36 & 1.97 & 1.52 & 1.95 \\
\hline & & \multicolumn{2}{|c|}{ SEd } & \multicolumn{2}{|c|}{ CD $(0.05)$} & \multicolumn{2}{|c|}{ SEd } & \multicolumn{2}{|c|}{ CD (0.05) } \\
\hline & $\begin{array}{c}\mathbf{T} \\
\mathbf{L} \\
\mathbf{T} \times \mathbf{L}\end{array}$ & \multicolumn{2}{|c|}{$\begin{array}{l}0.02 \\
0.01 \\
0.03\end{array}$} & \multicolumn{2}{|c|}{$\begin{array}{c}0.04 \\
0.02 \\
\text { NS }\end{array}$} & \multicolumn{2}{|c|}{$\begin{array}{l}0.02 \\
0.01 \\
0.04\end{array}$} & \multicolumn{2}{|c|}{$\begin{array}{c}0.05 \\
0.03 \\
\text { NS }\end{array}$} \\
\hline
\end{tabular}

$\mathrm{L} 1-1.5 \mathrm{dSm}^{-1} ; \mathrm{L} 2-3.0 \mathrm{dSm}^{-1} ; \mathrm{L} 3-4.5 \mathrm{dSm}^{-1} ; \mathrm{DAS}$ - Days after sowing, Values represent mean of three replicates;

Value in paranthesis indicate per cent increase over control; NS - not significant

G. intraradices - Glomus intraradices

S. calospora-Scutellospora calospora

TRY 1-Acaulospora sp

TRY 3- Glomus mosseae

TRY 2- Scutellospora sp.

TFS 1- Glomus aggregatum 
Figure 1. Effect of AM fungal isolates on nutrient uptake in Onion against various levels of salinity
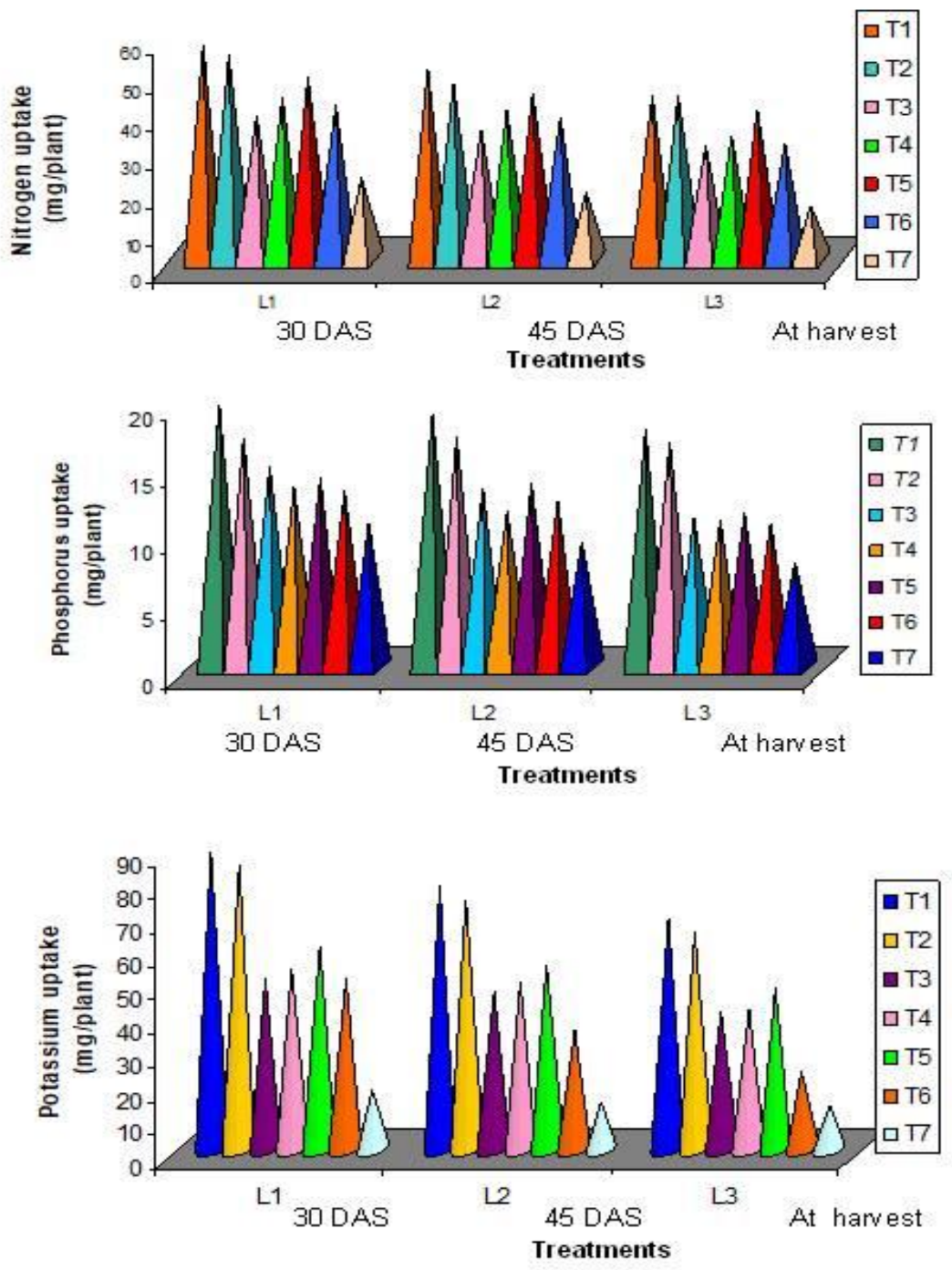

Treatments

T1 - Glomus intraradices T2 - Scutellospora calospora T3 - TRY 1 (Acaulospora sp.) T4 - TRY 2 (Scutellospora sp.) T5 - TRY 3 (Glomus mosseae) T6-TFS 1 (Glomus aggregatum T7 - Control
Levels

$$
\text { L1 - } 1.5 \mathrm{dSm}^{-1}
$$$$
\text { L2 }-3.0 \mathrm{dSm}^{-1}
$$$$
\text { L } 3 \text { - } 4.5 \mathrm{dSm}^{-1}
$$ 
Among the micronutrients analysed, iron was higher in soils than copper and zinc. Highest uptake of $6.17 \mathrm{ppm}$ iron was observed in T2 ( $S$. calospora) which was on par with T1 $(G$. intraradices). The content of copper was highest at $\mathrm{L} 1\left(1.5 \mathrm{dSm}^{-1}\right)$ in $G$. intraradices showing $0.40 \mathrm{ppm}$ and was on par with $S$. calospora inoculation while the the zinc contents were maximum in treatments with $G$. intraradices and $S$. calospora (2.68 and 2.66 ppm) (Table 9 a,b,c).

In the present study, the mycorrhizal plants showed noticeable increase in uptake of nitrogen than the control. Similar increase in $\mathrm{N}$ uptake has been reported in various crops which may be attributed to the contribution of hyphal transport of $\mathrm{N}$ in the form of $\mathrm{NO}^{-3}$ or $\mathrm{NH}^{-4}$ (Taylor et al., 1995). The enhanced $\mathrm{P}$ status in mycorrhizal plants might have altered the activities of $\mathrm{N}$ assimilating enzymes such as nitrate reductase (NR) and nitrate reductase (NIR). Better nutrient acquisition in mycorrhizal lettuce plants has been reported by Azcon et al., (2003) who explained that soil nitrogen (N) and phosphorus (P) levels are considered the most important factors among those, affecting AM association efficiency.

In this study, the uptake was decreasing with respect to increments in salt levels while maximum was observed at L1 $\left(1.5 \mathrm{dSm}^{-1}\right)$. At L3 $\left(4.5 \mathrm{dSm}^{-1}\right)$, the $\mathrm{N}$ uptake was decreased, still where AM inoculated treatments showed better concentrations than the control. This is in agreement with a studies by Rabie and Almadini (2005), who reported that inoculation of faba (Vicia faba) with mycorrhiza caused slight amelioration of nitrogen content and was significantly influenced due to mycorrhizal inoculations at all salinity levels compared to control plant and was reduced by about $64 \%$ at high salinity level.
Increase in phosphorus uptake was clearly observed at harvest in the present investigation in all the treatments except the control and this can be substantiated with the fact that increase in P uptake is attributed to the hyphal absorption and increased affinity towards ' $\mathrm{P}$ ' due to the presence of $\mathrm{PO}_{4}$ transporter compounds in the AM colonized roots. Effect of Glomus sp. in enhancing nutrient uptake was reported in a study by Giri et al., (2007) where root and shoot tissues of mycorrhizal plants showed apparently higher concentrations of ' $\mathrm{P}$ ' than non-mycorrhizal plants at all salinity levels. AM fungi have been shown to positively influence the composition of mineral nutrients of plants (especially poor mobility nutrients such as P) (Giri et al., 2003), by increasing tolerance as well as phosphorus availability under soil stress conditions (Sangeeta and Subodh, 2010) and they are directly involved in plant mineral nutrition (Uttam Tripura et al., 2016).

In this study, apart from the decrease in uptake of ' $\mathrm{P}$ ' with increments in salt level, an increase in uptake at each level of salt in the treatments showed the inoculation effect of the AM fungal isolates. Except in the $G$. intraradices and $S$. calospora inoculated treatments, the ' $\mathrm{P}$ ' uptake by other isolates was much less comparitively and still decreased at high salinity level (L3 - $4.5 \mathrm{dSm}^{-}$ ${ }^{1}$ ), which may be caused by the toxic effect of $\mathrm{Na}$ ions on AM fungal development. A similar decrease in $\mathrm{P}$ concentration has been reported earlier (Al-Karaki et al., 2001). It has also been reported that high salt content inhibits the growth of the AM fungal hyphae, which in turn reduced transport of $\mathrm{P}$ into roots and its uptake by the plant. (Mc Millen et al., 1998),

The phosphorus uptake is not only related to increased nutrient contents in mycorrhizal plants, but also to maintain plant health. Garg 
and Machanda (2009) explained that stress impeded the growth of plants, led to weight gain reductions in shoots as well as roots and nitrogen and phosphorus uptake, however, salt-stressed mycorrhizal plants produced greater root and shoot biomass, had higher phosphorus and nitrogen content than the corresponding uninoculated stressed plants. It is possible that improved plant nutrition by AM fungi allows cells to more effectively regulate and separate flowing ions. Ion pumps in the plasma membrane and tonoplast of root cells that bring about and maintain salt compartmentalization (Larcher, 1980) must be more efficient if the nutrition in the cell remains balanced. Reducing cell-membrane permeability by providing $\mathrm{P}$ via AM fungal hyphae to plant cells (particularly root cells) enhances cell structural organization. As cells are able to maintain membrane integrity under saline conditions, it is possible to avoid interference of excessive ions with metabolic processes (e.g., photosynthesis). These mechanisms strongly document that improved $P$ nutrition by AM fungi under saline conditions reduced the negative effects of $\mathrm{Na}^{+}$ and $\mathrm{Cl}^{-}$by maintaining vacuolar membrane integrity, which prevented these ions from interfering in growth metabolic pathways thereby influencing growth attributes (Cantrell and Lindermann, 2001).

In this study, potassium uptake was maximum at harvest in the $G$. intraradices and $S$. calospora treatments. $\mathrm{K}$ uptake was also mediated through the hyphal absorption. Increase in the concentration of $\mathrm{K}$ in mycorrhizal plants has also been reported previously (Mohammad et al., 2003; Giri et al., 2007) where mycorrhizal plants accumulated a higher concentration of $\mathrm{K}$ at all salinity levels. Higher water potentials, along with improved $\mathrm{K}$ nutrition by AM fungal in Onion, indicate mechanisms other than increased $\mathrm{P}$ nutrition may be important for plants growing under saline stress. These effects appear to be secondary to the effects of AM fungi on P uptake (Poss et al., 1985). It seems that higher $\mathrm{K}$ accumulation by mycorrhizal plants under salt stress conditions may help in maintaining a high $\mathrm{K} / \mathrm{Na}$ ratio, by preventing the disruption of various enzymatic process and inhibition of protein synthesis and thus another important effect of AM fungi, which may be related to salinity tolerance.

In this study, all the treatments were found to enhance the uptake at each level of stress still a gradual decline along with increasing salinity was observed. This concept is supported by some with previous observations also (Shokri and Maadi, 2009). The mycorrhizal $\mathrm{K}$ response (MKR) in shoots of Trifolium sp. showed that mycorrhizal effects on $\mathrm{K}$ uptake were generally higher at 30 days than at 10 days but decreased with increasing soil salinity at all harvests, although the extent of this difference decreased with increasing salinity between 3.5 and $12 \mathrm{dSm}^{-1}$ (Asghari, 2008). Lower $K$ concentrations in mycorrhizal plants are in accordance with the reduction in root surface and indicate a relatively low hyphal capacity for $\mathrm{K}$ delivery.

In the present study, increase in the micronutrient uptake (iron and copper significantly than zinc) was observed in the treatments at all the three levels of salt than the control. Hamel et al., (2000) also recorded increase in micronutrient contents due to inoculation of $G$. intraradices in Tomato. Giri et al., (2007) reported the effect of AM inoculation in soils, at 1.2, 4.0, and $6.5 \mathrm{dS} \mathrm{m}^{-1}$ salinity levels where mycorrhizal plants maintained greater root and shoot biomass at all salinity with higher $\mathrm{P}, \mathrm{Zn}$, and $\mathrm{Cu}$ concentrations than uninoculated plants. Also, micronutrient uptake by plants was descending along with increase in salinity levels and was lowest at L3, $\left(4.5 \mathrm{dSm}^{-1}\right)$ in this study. These results are in accordance 
with Giri et al., (2007) who showed the concentrations of $\mathrm{P}, \mathrm{Zn}$, and $\mathrm{Cu}$ were higher for mycorrhizal plants, but the magnitude decreased with increasing levels of salinity. A decrease in mycorrhizal colonization due to high soil phosphorus levels can lead to plant deficiencies in other micronutrients (Timmer and Leyden 1980). Though the available nutrients were influenced due to treatments the decrease in root colonization observed in this study may be the reason for such decrease in the uptake of nutrients. The reduced uptake of micronutrients with increase in the salt levels was also reported by Asghari (2008) who reported the difference was nonsignificant between the interactions.

With increasing salinity levels, Na uptake by plants was found to be increased in both mycorrhizal and nonmycorrhizal plants in the present study. AM inoculated plants showed significantly less uptake of sodium than the control at all the levels of salt while significant difference was not observed at high salt, L3 (3. $0 \mathrm{dSm}^{-1}$ ) Also Asghari, (2008) showed that at higher salt levels, the root $\mathrm{Na}$ concentration in mycorrhizal plants was significantly lower than non-mycorrhizal plants. This increase in plant sodium concentration above a particular stress level shows the intolerance of the inoculated species to high stress leading to interruption and reduced uptake of other essential nutrients at high salt levels.

Similarly, Pfeiffer and Bloss (1988) stated that the major effect of the mycorrhiza on sodium uptake is through mediation of phosphorus accumulation. Other mechanisms that improve salt tolerance may include maintaining membrane integrity (Rinaldelli and Mancuso, 1996) that would facilitate compartmentalization within vacuoles, and selective ion intake. Induction of osmotica could lead to osmotic adjustment (Duke et al., 1986), and improved and balanced nutrition in plants could also increase salt tolerance (Marschner, 1995). Such mechanisms could all involve salt tolerance effects of AM fungi. Among the treatments TFS 1 showed higher sodium contents in plants which may be due to intolerance of this species to survive the stress. Salinity affects the formation and function of mycorrhizal symbiosis (Giri et al., 2003). Mycorrhizal Onion roots generally had greater $\mathrm{P}, \mathrm{Fe}$, and $\mathrm{Cu} \mathrm{Na}$ concentrations (Cantrell and Lindermann, 2001).

In saline conditions, best results were obtained at moderate levels of salinity (3.5-5 $\mathrm{dS} / \mathrm{m}$ ) at 30 days after transplaning (Asghari, 2008). Improved mineral nutrition (AlKaraki and Al-Raddad, 1997), improved water potential (Marulanda et al., 2003), improved physiological processes (increased carbon dioxide exchange rate, transpiration, stomatal conductance and water use efficiency) (Ruiz-Lozano and Azcón, 2000) are the most important salinity tolerance mechanisms in mycorrhizal plants that have been reported.

In the present study, the soil nutrient status decreased with respect to age of the crop as well as increasing levels of the salt. The availability of nutrients getting lowered at harvest showed the increased uptake by the inoculated plants. The effects of $\mathrm{P}$ on soil aggregation may be indirect, as $\mathrm{P}$ availability affects shoot and root growth, and increases plant production and ground cover. The availability of $\mathrm{P}$ also influences colonization of arbuscular mycorrhizal fungi (AM fungi) (Facelli and Facelli, 2002), which affect root morphology and aggregation. Application of $\mathrm{P}$ as fertilizer and phosphoric acid can lead to the formation of $\mathrm{Al}^{3+}$ or $\mathrm{Ca}^{2+}$ phosphates, which act as aggregate bonding agents (Haynes and Naidu, 1998).

Also the higher available $\mathrm{N}: \mathrm{P}$ ratio suggests the promotion in crop growth. A high soil N:P 
ratio may promote the establishment of the plants, in association with AM fungi (Eschen et al., 2009). The level of AM fungal colonization of plant roots and its effect on plant growth may vary not only depending on the composition and abundance of the AM fungal species but also the available nutrients (Reynolds et al., 2006). The significant correlations between $\mathrm{N}: \mathrm{P}$ ratio, $\mathrm{P}$ and $\mathrm{K}$ concentrations in soil, and the fraction of colonized root length containing arbuscules across aboveground and belowground environment types reported by Blanke et al., (2005) and Eschen et al., (2009) confirmed the results that plants are more likely to encounter circumstances (biotic and abiotic stress conditions) that promote AM fungal colonization and show higher establishment rates.

In the present investigation inoculation due to G. intraradices showed significant increase in micronutrient contents and this is in line with Hamel et al., (1997) who showed inoculation with G. intraradices and G. versiforme responded positive to available nutrient content in soils of Leek plants.

\section{Acknowledgement}

I place my sincere thanks to my Professors, lab assistants, friends and family for rendering whole hearted support for undergoing this research.

\section{References}

Aliasgharzadeh, N., Rastin, N.S., Towfighi, H. and Alizadeh, A. 2001. Occurrence of arbuscular mycorrhizal fungi in saline soils of the Tabriz plain of Iran in relation to some physical and chemical properties of soil. Mycorrhiza, 11: 119-122.

Al-Karaki, G.N and Al-Raddad, A. 1997. Effects of arbuscular mycorrhizal fungi and drought stress on growth and nutrient uptake of wheat genotypes differing in drought resistance. Mycorrhiza, 7: 83-88.

Al-Karaki, G.N. 2000. Growth of mycorrhizal tomato and mineral acquisition under salt stress. Mycorrhiza, 10: 51-54.

Al-Karaki, G.N., Hammad, R. and Rusan, M. 2001. Response of two tomato cultivars differing in salt tolerance to inoculation with mycorrhizal fungi under salt stress. Mycorrhiza, 11:43-47.

Asghari. H.R. 2008. Vesicular-arbuscular (VA) mycorrhizae improve salinity tolerance in pre-inoculation subterranean clover (Trifolium subterraneum) seedlings. Intern. J. of Plant Prod., 2(3): 243-256.

Azcón, R., Ambrosano, E. and Charest, C. 2003. Nutrient acquisition in mycorrhizal lettuce plants under different phosphorus and nitrogen concentration. Plant Science, 165: 1137-1145.

Barea, J.M., Azcon, R. and Azcon-Aguilar, C. 1992. Vesicular-arbuscular mycorrhizal fungi in nitrogen-fixing systems. In: Methods in microbiology: technology for the study of mycorrhizae. (Eds.), J.R. Norris, D. Read, A. Varma. Academic Press, London. vol 24, pp. 391-416.

Blanke, V., Renker, C., Wagner, M., Fullner, K., Held M., Kuhn, A.J. and Buscot, F. 2005. Nitrogen supply affects arbuscular mycorrhizal colonization of Artemisia vulgaris in a phosphate-polluted field site. New Phytol., 166(3): 981-992.

Cantrell, C.I and Lindermann, R.G. 2001. Preinoculation of lettuce and onion with VA mycorrhizal fungi reduces deleterious effects of soil salinity. Plant soil, 233: 269281.

Duke, E.R., Johnson, C. R. and Koch, K. E. 1986. Accumulation of phosphorus, dry matter and betaine during $\mathrm{NaCl}$ stress of split-root citrus seedlings colonized with vesiculararbuscular mycorrhizal fungi on zero, one or two halves. New Phytol., 104, 583-590.

Eschen, R., Müller-Schärer, H. and Schaffner, U. 2009. Aboveground environment type, soil nutrient content and arbuscular mycorrhizal fungi explain establishment success of Centaurea jacea on ex-arable land and in late-successional grasslands. Plant and Soil, 322, 115-123.

Facelli, E, Facelli, J.M. 2002. Soil phosphorus 
heterogeneity and mycorrhizal symbiosisregulate plant intra-specific competition and size distribution. Oecologia, 133: 54- 61.

Garg, N and Manchanda, G. 2009. Role of Arbuscular Mycorrhizae in the Alleviation of Ionic, Osmotic and Oxidative Stresses Induced by Salinity in Cajanus cajan (L.) Millsp. (pigeonpea). J. Agron. Crop Sci., 195 (2): 110-123.

Giri, B., Kapoor, R. and Mukerji, K.G. 2003. Influence of arbuscular mycorrhizal fungi and salinity on growth, biomass and mineral nutrition of Acacia auriculiformis. Biol. Fert. Soils., 38: 170-175.

Giri, B., Kapoor, R. and Mukerji, K. G. 2007. Improved Tolerance of Acacia nilotica to Salt Stress by Arbuscular Mycorrhiza, Glomus fasciculatum may be Partly Related to Elevated K/Na Ratios in Root and Shoot Tissues. Microbial Ecology, 54: 753-760.

Hamel, C., Dalpe, Y., Furlan, V. and Parent, S. 1997. Indigenous populations of arbuscular mycorrhizal fungi and soil aggregate stability are major determinants of leek (Allium porrum L) response to inoculation with Glomus intraradices (Schenck and Smith) or Glomus versiforme (Karsten) Berch. Mycorrhiza, 7(4): 187-196.

Hamel, P., Olive, J., Pierre, Y., Wollman, F.A. and de Vitry, C. 2000. A new subunit of cytochrome b6f complex undergoes reversible phosphorylation upon state transition. J. Biol. Chem., 275: 1707217079.

Haynes, R.J and Naidu, R. 1998. Influence of lime, fertilizer and manure applications on soil organic matter content and soil physical conditions: a review. Nutr. Cycl. Agroecosyst., 51: 123-137.

Humphries. E.C. 1956. Mineral components and ash analysis. In: Modern method of plant analysis (Eds.). K. Peach and M.V. Tracey. Springer Verlag, Berlin. pp. 468-502.

Jackson. M.L. 1973. Soil Chemical Analysis. Prentice Hall of India Private Ltd., New Delhi, pp. 56-70.

Kohler, J., Caravaca, F. and Roldán, A. 2010. An $\mathrm{AM}$ fungus and a PGPR intensify the adverse effects of salinity on the stability of rhizosphere soil aggregates of Lactuca sativa. Soil Biology and Biochemistry, 42(3): 429-434.

Larcher. W. 1980. Physiological Plant Ecology. Springer-Verlag, New York.

Machado, R. and Serralheiro, R. 2017. Soil salinity: Effect on vegetable crop growth. Management practices to prevent and mitigate soil salinization. Horticulturae, 3(2): 30.

Marschner. H. 1995. Mineral nutrition of higher plants, 2nd edn. New York, NY: Academic Press.

Marulanda, A., Azcon, R. and Ruiz-Lozano, J.M. 2003. Contribution of six arbuscular mycorrhizal fungal isolates to water uptake by Lactuca sativa plants under drought stress. Physiologia Plantarum, 119: 1-8.

Mc Millen, B.G., Juniper, S. and Abbott, L.K. 1998. Inhibition of hyphal growth of a vesicular arbuscular mycorrhizal fungus in soil containing sodium chloride limits the spread of infection from spores. Soil Biol Biochem., 30: 1639-1646.

McGonigle, T.P and Fitter, A.H. 1988. Growth and phosphorus inflows of Trifolium repens $L$. with a range of indigenous vesicular-arbuscular mycorrhizal infection levels under field conditions. New Phytol., 108: 59-65.

Mohammad, M.J., Malkawi, H.I. and Shibili, R. 2003. Effects of arbuscular mycorrhizal fungi on soils with different levels of salts. J Plant Nutr., 26: 125-137.

Panse, V.G. and Shukatme, P.V. 1978. Statistical methods for Agricultural workers. Indian council of Agricultural Research, New Delhi, pp. 327.

Pfeiffer, C.M and Bloss, H. E. 1988. Growth and nutrition of guayule (Parthenium argentatum) in a saline soil as influenced by vesicular-arbuscular mycorrhiza and phosphorus fertilization. New Phytol., 108: 315-321.

Poss, J. A., Pond, E., Menge, J. A. and Jarrell, W. M. 1985. Effect of salinity on mycorrhizal onion and tomato in soil with and without additional phosphate. Plant Soil, 88: 307319.

Rabie, G.H and Almadini, A.M. 2005. Role of 
bioinoculants in development of salttolerance of Vicia faba plants under salinity stress. African Journal of Biotechnology, 4: 210-222.

Reynolds, H.L., Vogelsang, K.M., Hartley, A.E. 2006. Variable responses of old- field perennials to arbuscular mycorrhizal fungi and phosphorus source. Oecologia, 147: 348-358.

Rinaldelli, E. and Mancuso, S. 1996. Response of young mycorrhizal and non-mycorrhizal plants of olive tree (Olea europaea L.) to saline conditions. Short-term electrophysiological and Long-Term Vegetative Salt Effects. Advances in horticultural science. Firenze University Press. ISSN: 0394-6169.

Ruiz-Lozano, J.M and Azcon, R. 2000. Symbiotic efficiency and infectivity of an autochthonous arbuscular mycorrhizal Glomus sp. from saline soils and Glomus deserticola under salinity. Mycorrhiza, 10: 137-143.

Sanjoy kumar, S. Chaudhuri and Maiti, S. K. 2011. Assessment of VAM spore density and root infection from alluvial soil of eastern part of Raniganj coalfield areas. The bioscan, 6(3): 375-381.

Sangeeta Mukhopadhyay and Subodh Kumar Maiti. 2010. Natural mycorrhizal colonization in tree species growing on the reclaimed coalmine overburden dumps: Case study from Jharia coalfields, India. The Bioscan, Special issue, 3: 761-770.
Shahbaz, M. and Ashraf, M. 2013. Improving salinity tolerance in cereals. Crit. Rev. Plant Sci., 32: 237-249.

Shokri, S. and Maadi, B. 2009. Effects of Arbuscular Mycorrhizal fungus on the mineral nutrition and yield of Trifolium alexandrinum under salinity salinity stress. Journal of Agronomy, 8(2): 79-83.

Taylor, T. N., Remy, W., Hass, H. and Kerp, H.. 1995. Fossil arbuscular mycorrhizae from the Early Devonian. Mycologia, 87: 560573.

Timmer, L. and Leyden, R. 1980. "The relationship of mycorrhizal infection $t$ phosphorus-induced copper deficiency in sour orange seedlings". New Phytol., 85: $15-23$.

Turkmen, O., Sensoy, S., Demir, S. and Erdinc, C. 2008. Effects of two different AMF species on growth and nutrient content of pepper seedlings grown under moderate salt stress. African J. Biotechnol., 7(4): 392-396.

USEPA. 1979. Method 218.1, Atomic absorption direct asperiation. In: Methods for chemical analysis of water and wastes. Environmental monitoring and support laboratory,Cincinnati.

Uttam Tripura, N., Hegde, K. and Chaya P. Patil. 2016. Effect of planting dates and VAmycorrhiza on the performance of Turmeric (performance of turmeric (Curcuma longa L.) cv. salem. The Bioscan, 11(1): 459-462.

\section{How to cite this article:}

Srimathi Priya, L., K. Indhumathi, K. Kumutha and Pandiyarajan, P. 2020. Studies on Nutrient Acquisition by Mycorrhizal Plants at Various Levels of Induced Sodicity. Int.J.Curr.Microbiol.App.Sci. 9(09): 2186-2209. doi: https://doi.org/10.20546/ijcmas.2020.909.274 